\title{
An Overview of the Journal of Institute of Science and Technology: Problems, Challenges and Future Prospects
}

\author{
Prem Bahadur Budha \\ Central Department of Zoology, Tribhuvan University, Nepal \\ E-mail: pbbudha@cdztu.edu.np
}

\begin{abstract}
In its inception, the Journal of Institute of Science (JIS) was published in 1978 which was transformed to the Journal of Institute of Science and Technology (JIST) after the $7^{\text {th }}$ volume published in 1984. The journal publication was stopped from 1989 to 2001 and resumed again from 2002 onward. The journal was published in every two years' interval from 2002 to 2012, but with current chief editor, two issues in a year have been published from 2013 onward. The number of papers in JIST ranges from 3 to 32 comprising 1 page of review paper (vol. 18(2) in 2014) to 27 (vol. 3 in 1980). The most of contributing authors in all issues are mainly from Nepal with some contributors from India, China, Japan, Australia, Israel, Norway, USA, UK, Sweden, Spain, and Germany. Although the high quality papers have been used in the journal, paper citation rate is very poor due to its limited circulation in the academic market. The present paper highlights the past and current problems, challenges and future prospects to publish the journal efficiently with a view to make it available to wide range of readers with better quality papers.
\end{abstract}

Keywords: JIS, JIST, Journal, Impact Factor (IF), Science Citation Index (SCI).

\section{INTRODUCTION}

Performance Indicators (PIs) in higher education have chiefly focused on research outputs which are disseminated through peer review journals. Publication of quality journal is a difficult task and one of the most important indicators to measure research activities of any academic institution. The journal quality is measured through International Scientific Indexing (ISI) and Impact Factor (IF). A journal's IF is derived from the citations of the published articles in the scientific literatures. Although, most of the journals published in developing countries are rarely indexed in Science Citation Index (SCI). Only one Journal from Nepal, the Journal of Nepal Medical Association, has been catalogued into SCI (Thompson Reuters, 2013). Findings published in any regional and national journals of underdeveloped countries are equally important to the global scientific community because there is a large gap of information between developed and developing countries. However, the scientific production is very poor in developing countries, both in terms of quality and quantity due to the lack of support and incentives for research and development (R\&D) activities including basic infrastructure both from local governments and international agencies (Langer et al. 2004).

The history of journal publication in science and technology in Nepal is less than 5 decades. Within this period several journals have been published with a view to disseminate research findings in Nepal. But there is a bitter experience in publishing journals, maintaining their qualities and making the publications continue. The first journal of Nepal is probably the Journal of Science published in 1964 by Tri-Chandra College, Tribhuvan University (TU) which could not be brought out after its $5^{\text {th }}$ volume in 1973. A number of journals commenced their publications with enthusiasm at first but confined to its $1^{\text {st }}$ or a few more volumes in the history of continuation. For instance, Journal of Entomological Society of Nepal (single issue in 1989), Nepalese Journal of Zoology (initiated by Masters' students, single printed issue vol. 1 , no. 1 in 2006, Central Department of Zoology has tried to revive it as online version (www.cdztu.edu.np) but put the same volume name as the printed version but different articles vol. 1, issue 1 in 2013), Botanica orientalis (1998 to 2005, no further issues afterward), Himalayan Journal of Sciences (2003 to 2011) and many more. Although there were gaps in some years, some old journals have been sustained since their establishment, for example, Journal of Natural History Museum, TU (1977 to date), Journal of Institute of Science and Technology (1978 to date), Journal of Nepal Chemical Society (1981 to date), Bulletin of Department of Geology (1986 to date), Nepal Journal of Science and Technology (1999 to date). Many more journals have been emerging in the last decade of publications are being continued till date. There are 95 journals listed on NepJOL (http://nepjol.info) that provides access to Nepalese published researches and 
increase worldwide knowledge of indigenous scholars and fellows. It is supported by the International Network for the Availability of Scientific Publication (INASP). There are 557 Tables of Contents listing 7,776 articles and 7,051 of the articles are available in full text (pdf). These online journals are highly viewed by readers, viz. a total of 2,701,147 articles have been viewed since the opening of the site (Sept. 2007) till 2011. Journal of NELTA has the highest number of article views $(97,720)$ followed by Journal of Nepalese Business Studies $(77,430)$ and Our Nature $(58,159)$ during January-December 2011 but the Journal of Nepalese Business Studies tops in the list for the average number of viewers per article with 1,106 views followed by the Journal of Agriculture and Environment with 600 views and the International Journal of Life Sciences with 575 views (NepJOL, 2011). In addition, there are many more mushrooming journals which are not available online but have been produced by professional and non-professional groups particularly oriented to university promotion rather than providing quality information. Some individuals associated with some political organizations within University domain are engaged in so-called academic publications only aimed at promoting their positions which will lead to futile outcomes for the entire family of university and true academicians.

In this context, Journal of Institute of Science and Technology (JIST) is the official journal of Institute of Science and Technology (IOST), TU. This paper is primarily focused on the overview of the historical background of JIST, its problems, challenges and future prospects.

\section{MATERIALS AND METHODS}

This paper is prepared upon the request from the current chief editor of JIST (Prof. Dr. T.R. Aryal) to know the status of the journal from its inception and recommend timely publication with better manuscript, presentation and editorial quality in future. All issues of JIST were studied at the documented section of the Central Library, TU, Kirtipur including the upcoming issue (vol. 19, no. 2) provided by the current chief editor. The number of articles, single/double/multiple authors, number of pages, editorial board members of each issue were tabulated in excel sheet to produce graphical presentation. Observations and informal interviews were also made with Ex-chief editors, namely; Prof. Dr. C.L. Gajurel, Prof. Dr. P.N. Mishra, Prof. Dr. L.N. Jha and along with the current Chief editor Prof. Dr. T.R. Aryal in order to know their views on the development trends of the JIST journal and problems being faced during publication. Online journals of Nepal were also viewed in the website of NepJOL (http://www.nepjol.info). The cited previously published papers were counted from first 6 volumes and the recent two volumes. Distribution procedures of the journal were also discussed with responsible personalities of IOST.

\section{RESULTS AND DISCUSSION}

\section{Inception of JIST}

The research priority of TU was set by the New Education System Plan (NESP) in 1972/73 and National Development Service (NDS) was also launched for the Degree students to stay one year in the rural areas in Nepal. It was made mandatory to submit a Village Profile Report at the end of the NDS programme as part of the field research in addition to the Master's dissertation run by some departments of TU. Due to lack of any journal to disseminate the research findings, few dedicated faculty members C.L. Gajurel (Chemistry), D.N. Bajracharya (Botany), D.R. Mishra (Physics), and P.N. Mishra (Zoology) of Kirtipur Multiple Campus (now University Campus, Kirtipur, TU) took initiation to publish the multidisciplinary science journal, The Journal of Institute of Science (JIS) which was appreciated by the then Dean IOST, D.R. Uprety (per. commun. with Prof. Dr. C.L. Gajurel \& Prof. Dr. P.N. Mishra). The advisory board of 11 members was formed under the chairmanship of the D.R. Uprety and seven member's editorial board was made under C.L. Gajurel (Chief editor) including members of different science subjects D.N. Bajracharya, D.R. Mishra, P.N. Mishra, R.P. Manandhar (Mathematics), D.B. Chhetri (Statistics), and V.M. Pradhan (Geology). The first volume was published by Kirtipur Multiple Campus in 1978 with limited resources generated by editorial board members. The name of the publishers of the journal indicated in the cover page are different from volume 1 to 6 (Kirtipur Multiple Campus, TU), volume 7 to 11 (TU) and volume 12 to current issue (IOST, TU) (Fig. 1). Since the beginning, five chief editors were appointed by the Dean's Office, TU for publishing different issues for the last 36 years. The list of Chief editors and their tenure, journal volumes, average number of papers they are published are given in Table 1.

After the $6^{\text {th }}$ volume, the name of the "Journal of Institute of Science (JIS) has been transformed to the "Journal of Institute of Science and Technology (JIST)" Fig. 1). There are 26 articles and two short communications of 12 single authors, 13 double authors, and 3 multiple authors' papers in the $1^{\text {st }}$ volume. The number of articles and pages varies from 3 articles/24 pages in 1986 to 32 articles/265 pages in 1980 . The most of contributing authors in all issues are mainly from Nepal with some contributors from India, China, Japan, Australia, Israel, Norway, USA, UK, Sweden, Spain, and Germany. 
Table. 1 Chief Editors of JIST

\begin{tabular}{lc|c|ccc}
\hline \multicolumn{1}{c|}{$\begin{array}{c}\text { Name of chief editor } \\
\text { (subject) }\end{array}$} & Volume & $\begin{array}{c}\text { No. of papers published } \\
\text { during the tenure }\end{array}$ & Year & $\begin{array}{c}\text { Advisory } \\
\text { member(s) }\end{array}$ & $\begin{array}{c}\text { Editorial } \\
\text { members }\end{array}$ \\
\hline Dr. C.L. Gajurel (Chemistry) & $1-3$ & 90 papers during 3 years & $1978-1980$ & 10 & 7 \\
Dr. K.K. Joshi (Botany) & $4-5$ & 41 papers during 2 years & $1981-1982$ & 7 & 7 \\
Dr. P.N. Mishra (Zoology) & $6-11$ & 38 papers during 6 years & $1983-1888$ & 9 & 9 \\
Dr. L.N. Jha (Physics) & $12-17$ & 90 paper during 11 years & $2002-2012$ & 1 (Dean) & 6 \\
Dr. T.R. Aryal (Statistics) & 18(1\&2)-19(1\&2) & 102 papers during 2 years & $2013-2014$ & 1(Dean) & 6 \\
\hline
\end{tabular}

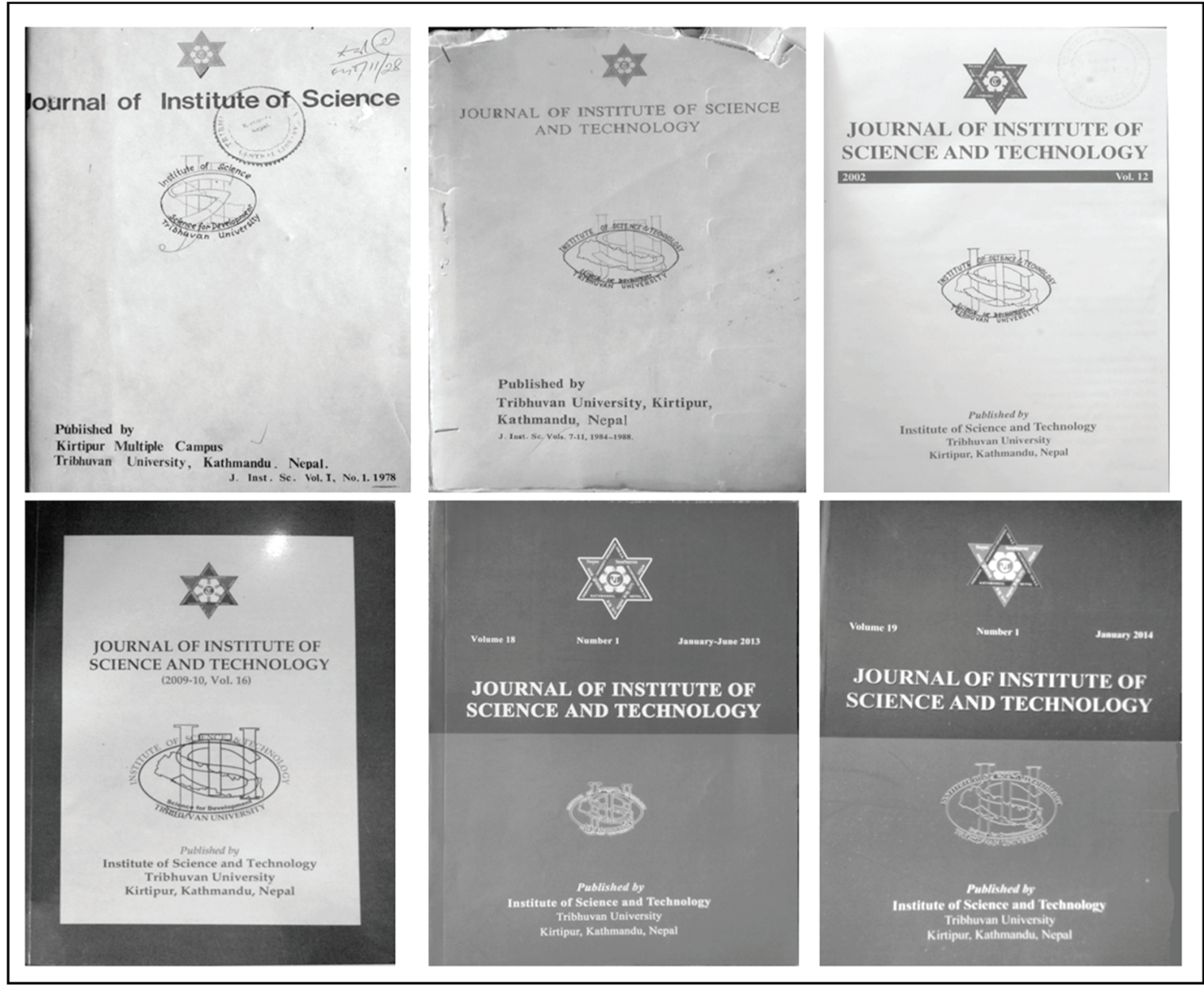

Fig. 1. Some issues of JIST showing different publishers, years of publication and volumes \& volume numbers

The journal was published regularly up to the $6^{\text {th }}$ volume till 1983 but the later volumes became irregular due to financial constraints (per. commun. with Prof. Dr. P.N. Mishra \& Prof. Dr. L.N. Jha). The volumes 7-11 (1984-88) were published together with the single binding but the volume number and articles were maintained to sustain the volume number consistent. Unfortunately the journal remained unpublished from 1989 to 2001 . Realizing the importance of the research activities within TU and need of the journal, the Dean's Office took initiation to revive the journal and published the $12^{\text {th }}$ volume in 2002 after
12 years break. Although, it was not regularly published every year till 2012 but continued publishing within the interval of one or two years (Fig. 2). The current Dean of IOST (Mrs. Chirika Shova Tamarakar) took initiation to allocate resources to speed up the journal publication since 2013. The current chief editor has been publishing two issues in a year (vol. 18, no. $1 \& 2$ ) with four colour cover page, good quality paper and increased journal size to A4. Out of two issues of 2014, January-July issue (vol. 19 , no. 1) is already published as early issue and JulyDecember issue (vol. 19, no. 2) is at hand. 
Quality and Number of Papers in each Volume of JIST

JIST is the multidisciplinary science journal which offers articles, short communications, reports, comments/notes and letters in different aspects of various disciplines of science and technology. The published papers are grouped into biological (zoology, botany, biotechnology, microbiology and environmental sciences), mathematical (mathematics, statistics and computer sciences) and physical (physics, chemistry, geology, meteorology and hydrology) sciences. Altogether 361 articles and 2903 pages have been published from JIS to the JIST. The highest number of papers belonging to chemistry (69) followed by zoology (68), botany (55) and the rest are other disciplines (Table 2). The number of papers from the biological sciences is the highest in comparison to physical and mathematical sciences (Fig. 2). Within biological science papers from botany and zoology comprise the highest in number (34\%) out of the total published articles. An average number of papers of biological, physical and mathematical sciences are 8.2, 5.5 and 3.2 respectively. The length of the articles ranges from a single page as review paper (vol. 19, no. 1, p. 160) to 27 pages (vol. 2, no.1, pp. 223-250).

Table 2. Articles of different science discipline published in JIST (1978-2014)

\begin{tabular}{|c|c|c|c|c|c|c|c|c|c|c|c|c|c|c|c|c|c|c|c|c|c|c|}
\hline \multirow[b]{2}{*}{ Subjects } & \multicolumn{21}{|c|}{ Volumes(Number) } & \multirow[b]{2}{*}{ Total } \\
\hline & 1 & 2 & 3 & 4 & 5 & 6 & 7 & 8 & 9 & 10 & 11 & 12 & 13 & 14 & 15 & 16 & 17 & $18(1)$ & $18(2)$ & $19(1)$ & $19(2)$ & \\
\hline Botany & 2 & 2 & 5 & 9 & 12 & 5 & 1 & 2 & 2 & 1 & 1 & 4 & 3 & 1 & 0 & 3 & 1 & 0 & 1 & 0 & 0 & 55 \\
\hline Chemistry & 11 & 8 & 9 & 5 & 2 & 1 & 1 & 1 & 0 & 0 & 0 & 3 & 4 & 2 & 1 & 3 & 4 & 5 & 4 & 3 & 2 & 69 \\
\hline Mathematics & 4 & 9 & 5 & 0 & 2 & 1 & 1 & 0 & 0 & 0 & 0 & 0 & 0 & 0 & 0 & 1 & 1 & 2 & 3 & 4 & 5 & 38 \\
\hline Physics & 2 & 2 & 1 & 0 & 1 & 2 & 1 & 1 & 0 & 0 & 0 & 1 & 0 & 1 & 5 & 3 & 4 & 4 & 5 & 4 & 5 & 42 \\
\hline \begin{tabular}{|l|} 
Statistics \\
\end{tabular} & 1 & 0 & 0 & 1 & 0 & 1 & 0 & 0 & 0 & 1 & 0 & 1 & 3 & 1 & 0 & 0 & 1 & 4 & 5 & 4 & 3 & 26 \\
\hline Zoology & 7 & 7 & 9 & 3 & 3 & 3 & 1 & 1 & 0 & 1 & 1 & 3 & 2 & 2 & 0 & 1 & 3 & 4 & 5 & 5 & 7 & 68 \\
\hline Geology & 0 & 0 & 0 & 1 & 0 & 0 & 0 & 0 & 0 & 0 & 0 & 0 & 0 & 1 & 0 & 0 & 0 & 1 & 0 & 3 & 0 & 6 \\
\hline Engineering & 0 & 0 & 0 & 0 & 0 & 0 & 0 & 0 & 0 & 0 & 0 & 0 & 0 & 0 & 0 & 0 & 0 & 0 & 1 & 2 & 0 & 3 \\
\hline Computer & 0 & 0 & 0 & 0 & 0 & 0 & 0 & 0 & 0 & 0 & 0 & 0 & 0 & 0 & 0 & 0 & 0 & 0 & 1 & 0 & 0 & 1 \\
\hline Microbiology & 0 & 0 & 0 & 0 & 0 & 0 & 0 & 0 & 0 & 0 & 0 & 1 & 1 & 2 & 3 & 4 & 1 & 0 & 0 & 0 & 0 & 12 \\
\hline Environment & 0 & 0 & 0 & 0 & 0 & 0 & 0 & 0 & 0 & 0 & 0 & 1 & 0 & 1 & 2 & 0 & 2 & 5 & 0 & 0 & 4 & 15 \\
\hline Biotech & 0 & 0 & 0 & 0 & 0 & 0 & 0 & 0 & 0 & 0 & 0 & 0 & 0 & 0 & 0 & 0 & 1 & 0 & 0 & 0 & 0 & 1 \\
\hline Others & 0 & 1 & 2 & 1 & 0 & 1 & 1 & 0 & 1 & 2 & 3 & 1 & 1 & 2 & 3 & 1 & 0 & 0 & 0 & 1 & 0 & 21 \\
\hline No of articles & 28 & 30 & 32 & 21 & 20 & 14 & 6 & 5 & 3 & 5 & 5 & 15 & 14 & 13 & 14 & 16 & 18 & 25 & 25 & 26 & 26 & 361 \\
\hline No of pages & 193 & 223 & 265 & 200 & 170 & 102 & 47 & 26 & 24 & 32 & 32 & 145 & 142 & 146 & 150 & 160 & 214 & 168 & 144 & 160 & 144 & 2887 \\
\hline Avg.pp/article & 6.9 & 7.4 & 8.3 & 9.5 & 8.5 & 7.3 & 7.8 & 5.2 & 8.0 & 6.4 & 6.4 & 9.7 & 10.1 & 11.2 & 10.7 & 10.0 & 11.9 & 6.7 & 5.8 & 6.2 & 5.5 & 8.0 \\
\hline
\end{tabular}

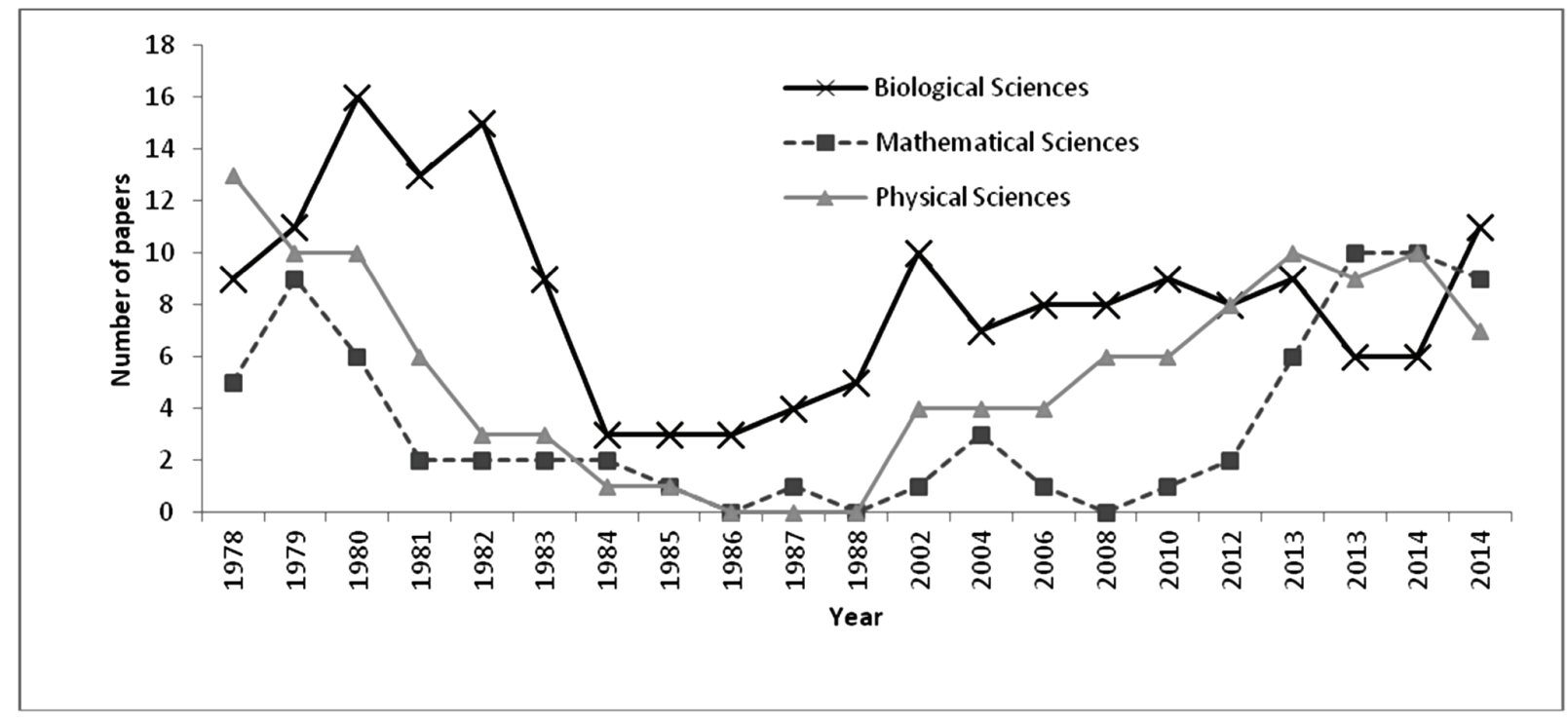

Fig. 2. Trends of published papers by science disciplines in JIST 
The papers published in JIST have remarkable contribution to science and technology. For instance, as this author belonging to biological sciences, the new species to science were discovered such as Xiphidiocercaria: Cercaria bheemnagarensis by Sharma and Mishra, 1979 (vol. 2, pp. 197-202); Echinostome Cercaria: Cercariae geetapalliensis by Pandey and Sharma, 1979 (vol. 2, pp. 203-208) and Echinostome Cercaria: Cercaria chillavanensis by Agrawal and Sharma 1980 (vol. 3, pp. 215-220), however, their taxonomic validity need to be confirmed. In addition, many contributions to scientific community from mathematical and physical sciences are also published in JIST till date.

\section{Citation Rate of Papers of JIST}

The citation of published papers is the indicator of its quality and availability to the readers. The JIST is not made available online yet. In the beginning, there was a provision to provide 25 reprints of the published papers to author(s) in addition to a copy of the journal but now instead of reprint copies, a pdf file of the concerned paper along with a hard copy of the journal are made available to the author(s). A system of sending a hard copy of the journal to the paper peer reviewers is also made available along with the token money of Rs. 1000 per reviewed paper which is orally agreed upon at the meeting by the Dean of the IOST but it is yet to be implemented (per. commun. with Prof. Dr. T.R. Aryal). Only one hard copy of the journal is provided to the group of multiple authors and distributions of the journals to general readers are limited to few libraries. On one hand there seems the scarcity of the journal in the market but on the other hand the large numbers of journals are stocked in stores without proper distribution to the readers. An awful example is that the author of this article wasted one and half month to locate misplaced old issues of the journal in the Central Library, TU, Kirtipur. During the course of writing review of JIST, author found thousands of copies of all old issues (vol. 1 to 6) of JIST have been dumped in an open gallery of the Central Department of Physics, TU, Kirtipur (Fig. 3) as soon as the retirement of the then Chief editor. This evidence clearly indicates the condition of the distribution system of the journal which has to be seriously improved in future.

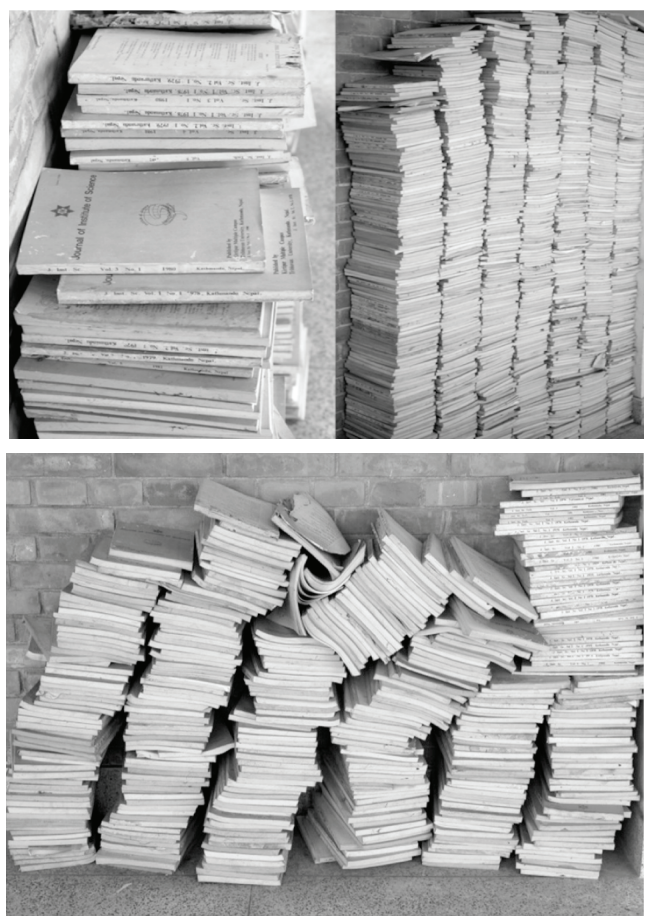

Fig. 3. Thousands of Copies of JIST, dumped in gallery of the Central Department of Physics, Kirtipur

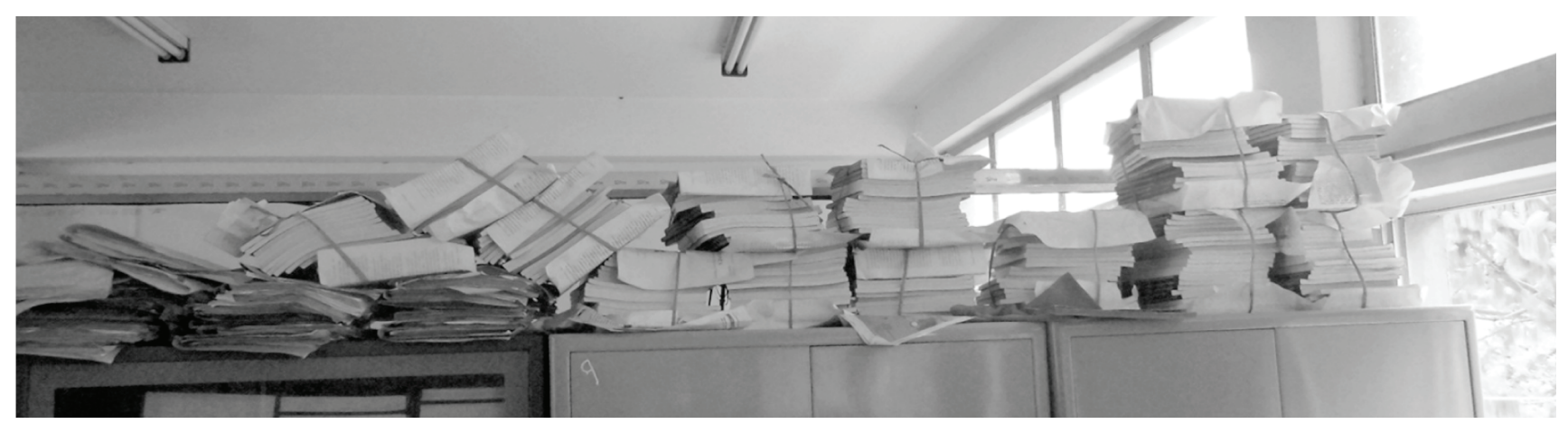

Fig. 4. Recent issues of JIST deposited at Dean's Office, TU

The poor distribution of the journal is the main reason of the low citation rate of the published papers. The citation of the JIST papers by JIST contributors is also very low which is represented by 2 in vol. 2,5 in vol. 3,3 in vol. 4,1 in vol. 5,3 in vol. 18 , no. 2 and 5 in vol. 19 , no. 1 . Unless we disseminate research findings by distributing publication either online or the printed copies to a wide range of libraries, colleges, scientists and general readers, the findings become worthless. The papers of current volumes (vol. 18, nos. $1 \& 2$ and vol. 19 , nos. $1 \& 2$ ) are made ready for online friendly version but the little initiation to upload the provided documents online has yet to be taken by responsible person of the Dean's Office (per. commun. with Prof. Dr. T.R. Aryal), 
and all recent printed volumes of JIST are still stored in the Dean's Office (Fig. 4).

\section{Challenges and Problems in Publishing Institutional Journals}

Publishing journals in Nepal come across a series of problems and challenges particularly those belonging to the institutions. Financial constraints, lack of efficient writing tendency among majority of contributors, negative attitude of authors toward good reviewers such as neither contributors defend their statements nor incorporate creative comments timely, poor English language of contributors whose mother tongue is not English, poor quality of reviewers and their biasness, weak research infrastructure such as out-dated library stock, high journal subscription fees and poor Internet Access availability, lack of advanced tools and techniques for quality analysis and lack of self-learning practices among contributors to use freely available software, waste of financial resources at unproductive meetings, encouragement to write single author papers than the joint authors due to dividing marks received by authors in university promotion, editors rely on bureaucratic processes to review, print, and distribute the published journal, lack of computer manpower to design and layout the papers in time. The burden of journal publication will mainly go to the chief editor if the selection and formation of the whole editorial board and supporting resources and staffs are not done wisely. In addition, there are so many bureaucratic hurdles to be faced in the course of journal publication. For instance, Dean Office has the website, however, there is no manpower to execute it and has no proper billing system for the distribution of the journals (per. commun. with Mr. Shree Bhadra Acharya \& Mr. Krisha Hari Acharya).

\section{Improving Journal Quality: Few Recommendations}

There is a long way to go to make the journal international standard. However some of the papers meet the international standard, many of them seem to be improved and upgraded their qualities as par with international level (per. commun. with Prof. Dr. T.R. Aryal). The prime focus should be given to make it at least highest standard at national level. So that authors should feel proud to publish their research findings in JIST. Several things to be improved such as checking whether the manuscript has updated recent data with original information, improvement of the English language, consistency in providing full references, improved quality of image and graph, continuation of the publication and its wider circulation. The quality improvements of the journals include three groups of people with their independent but relevant roles: the authors, the reviewers and the editors. Besides, the supporting resources and staffs should not be forgotten to have as a relevant role in the journal publication. Peer review and editing is the key factor to improve the quality of journals. Strict independent peer review system requires to be adopted to assess the quality of the manuscripts received. But editors of JIST have been facing with numerous problems in relation to authors which are shortage of quality manuscripts and poor quality of reviewers. Before going to the peer review system the editorial board of JIST has to improve the following steps; i) Establish a proper working office with own computer designing manpower, ii) Clear and detailed instructions how to write the manuscripts, iii) Inclusion of the editorial message to readers, iv) Selection of efficient chief editor along with editorial board members, v) Provision of language editor, vi) Publishing the journal online for wider circulation, getting the full authority to print and distribute the hard copies, and vii) Producing special issues for some particular areas of national relevance and information gaps. In nutshell, the journal publication should be strictly handled by a single basket policy by giving full responsibility as well as needy resources to the chief editor.

\section{ACKNOWLEDGEMENTS}

I would like to thank to chief editors of JIST Prof. Dr. C.L. Gajurel, Prof. Dr. P.N. Mishra, Prof. Dr. L.N. Jha and Prof. Dr. T.R. Aryal for sharing their views on telephone conversations. Similarly I would like to thank Ms. Radhika Maiya Bajracharya, Deputy Librarian of the Central Library, TU for helping to find the missing copies of the old issues of JIST.

\section{REFERENCES}

Journal of Institute of Science. vol. 1(1978), vol.2(1979), vol.3 (1980), vol.4(1981), vol.5(1982), vol.6(1983), vol.7-11(1984-88).

Journal of Institute of Science and Technology. vol.12 (2002), vol.13 (2004), vol.14 (2006/07), vol.15 (2009/10), vol.16 (2010/11), vol.17 (2012), vol.18, no. 1 \& 2 (2013), vol.19, no. 1 \&2 (2014).

Langer, A., Díaz-Olavarrieta, C., Berdichevsky, K., and Villar, J. 2004. Why is research from developing countries underrepresented in international health literature, and what can be done about it? Bulletin of the World Health Organization 82(10): 802-803.

NepJOL, 2011. NEPJOL Newsletter, Nepal Journal Online, No. 8, January-December, 2011.

Thompson Reuters, 2013. Source publication list for web science, Science Citation Index expanded. http://thomsonreuters.com. 